\title{
Building Information Modelling Skills in Construction- Related Disciplines: A Social Network and Job Advertisement-Based Comparative Analysis
}

\author{
Rahimi A. Rahman ${ }^{1 *}$, Steven K. Ayer ${ }^{2}$, Pingbo Tang ${ }^{3}$, and Matthew Eicher ${ }^{4}$
}

\begin{abstract}
Previous research efforts have attempted to identify the necessary Building Information Modelling (BIM) skills for individuals. However, prior works did not explore those needed for entry-level positions, and may be susceptible to respondents' bias. This study proposes using methods that do not require individual responses to identify those skills that are related to BIM. Specifically, the authors suggest using publicly available data on social networking profiles. This paper presents the results of the authors' research on identifying skills that are related to BIM and how they might be used in the industry. This study identifies those skills for graduating students by analysing social networking profiles and entry-level job advertisements. Additionally, the job tasks in those advertisements are analysed to illustrate how the skills might be used. This study performs those analyses to answer the following: (1) How do the skills differ between those that are possessed by individuals related to BIM and those that are listed in entry-level job advertisements that require BIM? And (2) How do the job tasks differ between BIM-specialized and nonBIM-specialized positions from the same entry-level job advertisements? The results suggest that there are discrepancies between the skills identified from the profiles and the advertisements. Additionally, while BIM skills may be a standard expectation in all positions in the future, there are BIM tasks that may disappear when BIM reaches maturity in the industry. Identifying and prioritizing the critical skills based on this type of analysis may enable educators to better prepare students for long-term success.
\end{abstract}

\section{Keywords}

BIM education, Building Information Modelling, skills, social network, job advertisement.

\footnotetext{
${ }^{1}$ School of Sustainable Engineering and the Built Environment, Arizona State University, P.O. Box 870204, Tempe, AZ, 85287-0204, USA. Tel.: +1-480-727-4616. *Corresponding Author: E-mail: $\underline{\text { r.rahimi @asu.edu }}$

${ }^{2}$ School of Sustainable Engineering and the Built Environment, Arizona State University, P.O. Box 870204, Tempe, AZ, 85287-0204, USA. Tel.: +1-480-727-4579. E-mail: steven.ayer@asu.edu

${ }^{3}$ School of Sustainable Engineering and the Built Environment, Arizona State University, P.O. Box 870204, Tempe, AZ, 85287-0204, USA. Tel.: +1-480-727-8105. E-mail: tangpingbo@asu.edu

${ }^{4}$ School of Sustainable Engineering and the Built Environment, Arizona State University, P.O. Box 870204, Tempe, AZ, 85287-0204, USA. Tel.: +1-480-727-6474. E-mail: eicher@asu.edu
} 
This paper presents the results of the authors' research on identifying skills that are related to BIM and how they might be used in the industry. This study identifies those skills for graduating students by analysing social networking profiles and entry-level job advertisements. Additionally, the job tasks in those advertisements are analysed to illustrate how the skills might be used in the industry. Specifically, this study performs those analyses to answer the following questions: (1) How do the skills differ between those that are possessed by individuals related to BIM and those that are listed in entry-level job advertisements that require BIM? And (2) How do the job tasks differ between BIM-specialized and non-BIM-specialized positions from the same entry-level job advertisements? To answer those questions, the authors analyse professionals' social networking profiles from LinkedIn to identify skills that are correlated with 'BIM.' Then this study analyses online job advertisements from LinkedIn and Indeed to identify skills that are listed, and job tasks in positions that require 'BIM.' Finally, the skills and job tasks are compared.

the necessary BIM skills for individuals. However, although the efforts provide insights on BIM skills, they did not explore those needed for entry-level positions. Additionally, there are efforts that have identified BIM skills using survey-based approaches (Ku and Taiebat, 2011; Wang and Leite, 2014a). While surveys can provide effective perception-based feedback, they may also be susceptible to respondents' bias. Therefore, this study proposes using methods that do not require individual responses to identify those skills that are related to BIM. Specifically, the authors of this work suggest leveraging publicly available data from social networking websites to observe the BIM skills that are commonly claimed and endorsed by construction professionals in several major cities throughout the United States of America (US). Additionally, the authors propose comparing this data with entry-level job advertisements selected from the same cities. The same entry-level advertisements are also explored to compare the job tasks between positions with 'BIM' in the title (BIM-specialized positions) and positions without 'BIM' in the title (non-BIMspecialized positions). The exploration of both sets of data may help to validate or question the findings of the prior research.

\section{Background}

Identifying skills that are related to BIM may help the education community to prepare students with the appropriate BIM skills. Previous research efforts have also attempted to identify skills relevant to BIM implementation in the construction industry. These efforts include analysing job advertisements (Barison and Santos, 2011; Uhm et al., 2017), published literature on BIM (Succar et al., 2013), and social networking profiles (Rahman et al., 2016a; Rahman et al., 2016b). There are also attempts in identifying BIM skills needed in graduating students by conducting questionnaire surveys (Ku and Taiebat, 2011; Wang and Leite, 2014a). These research efforts have provided valuable information on those fundamental BIM skills that may assist the advancement of BIM education. However, previous research focuses on more experienced positions such as project managers (Wang and Leite, 2014a) and BIM managers (Barison and Santos, 2011; Wang and Leite, 2014a). While surveys can provide effective perception-based feedback, they may also be 
susceptible to respondents' bias, which may illustrate a higher response rate from individuals who are actively engaged in BIM efforts and may not adequately represent the perception of the entire industry. This study proposes using methods that do not require individual responses to identify those skills that are related to BIM. Specifically, the authors suggest using publicly-available data of social networking profiles.

Other studies have also attempted to explore data such as the endorsements and profiles from social networking websites. However, the focus on endorsements includes proposing new methods to compute artificial data (Pérez-Rosés and Sebé, 2015), and improve data consistency (Pérez-Rosés and Sebé, 2016). Also, several studies focused on exploring social networking profiles to provide recommendations for improving employability (Zide and Shanani-Denning, 2014; Chiang and Suen, 2015). However, these studies do not focus on analysing raw data that already exists in social networking profiles. Therefore, the authors attempt to use those raw data to identify skills that are possessed by individuals. The previous works of the authors include identifying skills that have a connection in improving career success (Rahman et al., 2016a), and comparing the BIM skill set of project managers and BIM managers (Rahman et al., 2016b). Additionally, this study proposes comparing the skills identified from social networking profiles with the skills that can be identified using another publicly-available data set of job advertisements.

Understanding the job tasks that are related to a skill may illustrate how that skill is used in the industry. However, part of the challenge with identifying best practices for BIM education may be due to the differences in how BIM skills are implemented in the industry. Some companies may want a consistent BIM skill set among all new employees, while others may seek individuals with skill sets for specialized BIM positions such as BIM managers, BIM coordinators, or other BIM specialists (Gu and London, 2010; Sacks and Pikas, 2013). Additionally, these BIM-specialized positions may help to deliver the potential benefits of implementing BIM in construction projects (Succar, 2009). The job tasks of these BIM- specialized positions may contribute to the success of integrating BIM in construction projects (Merschbrok and Munkfold, 2015). In other words, because BIM skills are used differently in different organizations, there are also exclusive tasks for BIM-specialized positions.

This study initially analyses the job tasks in entrylevel job advertisements that require BIM to help illustrate how graduating students may be expected to use their BIM skills in the industry. However, there should be differences between the job tasks of BIM-specialized and non-BIM-specialized positions from the existence of those exclusive tasks. Therefore, the authors compare the job tasks between those positions in the advertisements to further illustrate the different usage of BIM skills in the industry.

\section{Methodology}

This study analyses information from social networking profiles and entry-level job advertisements to answer the research questions. The process of analysing this information involves collecting data from social networking and job advertisement websites. This process is followed by comparing the skills from the profiles and advertisements. Finally, this process ends by comparing job tasks between BIM-specialized and non-BIM-specialized positions from the advertisements. The following subsections discuss the methods of collecting and analysing information from social networking profiles and entry-level job advertisements.

\section{Data collection}

BIM may be used differently in different locations throughout the nation as well as around the world. In an attempt to identify skills that are commonly required throughout the country, several major metropolitan areas across the country are strategically selected. The cities include: (1) Phoenix, Arizona; (2) Los Angeles, California; (3) Seattle, Washington; (4) Chicago, Illinois; (5) New York City, New York; (6) Washington D.C.; (7) Jacksonville, Florida; and (8) Houston, Texas. Seven of those cities have either the largest 
population or the highest GMP in their region. Phoenix, in particular, was selected for the authors to both broaden their perspective on trends while advancing the curriculum at their home institution.

This study collects information from LinkedIn social networking profiles. Figure 1 presents the steps taken to identify the profiles. The authors use the search term 'BIM' in the available search feature to identify the profiles. The profiles are filtered to the 'construction' industry, and the eight targeted locations. The profiles are also filtered to 'people,' which removes organizations, job advertisements, and groups from the search results. The search feature limits the results to one thousand profiles per search results. This restriction led to locations with more than one thousand profiles having a lower percentage of profiles collected. The data collection involves collecting the name, location, industry, skills, and endorsements from each accessible profile. The names, locations, and industries are used to remove duplicate profiles and profiles out of scope while the skills and endorsements are used for data analysis. The 'skills and endorsements' feature in LinkedIn allows individuals to list skills in their profiles. Other individuals can endorse those skills or nominate other unlisted skills to be added to the profiles. Since the feature permits individuals to list or designate skills in a free manner, skills that differ based on their letter case, singular and plural forms, additional special characters, or extra spaces are grouped together in this process.

Additionally, this study collects information from entry-level job advertisement listed on LinkedIn and Indeed. The authors select these two websites because they have the highest search results compared to other typical job advertisements sites in the country. This study uses the search term 'BIM' in the available search feature on those websites to identify the advertisements. This approach collects only advertisements that have 'BIM' in their list of skills to remove positions that have no requirement for BIM. In this process, only academic qualifications related to civil engineering, construction engineering, and construction management are collected. Additionally, only positions that do not require work experience besides internships are regarded as entry-level positions. The data collection involves collecting the name, company, location, summary of the positions, job tasks, and skills. The names, companies and locations are utilized to remove duplicate advertisements in the data while the summary of positions, job tasks, and skills are used for data analysis.

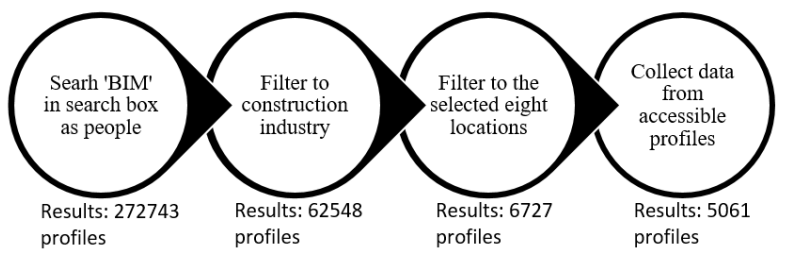

Figure 1 The process of identifying social networking profiles in LinkedIn

\section{Data analysis: Skills possessed by individuals vs. skills listed in job ads}

This analysis compares skills from the collected profiles and advertisements. The process of analysing those skills involves: (i) Identifying skills that are correlated with 'BIM' from those social networking profiles; (ii) Identifying skills that are commonly listed in those job advertisements that require 'BIM;' and (iii) Comparing the data that have been identified in (i) and (ii). This subsection describes the methods of analysing the skills from the profiles and advertisements. Figure 2 shows the steps performed in this analysis.

\section{Skills correlated with BIM in social networking profiles}

This study proposes a new method to identify skills that have a correlation with a particular skill from the social networking profiles. The method performs bivariate correlation analysis on the skills derived from the 'skills and endorsements' feature from LinkedIn. The same methodology could potentially be applied to any social network-based data source, but LinkedIn is chosen for its standing as the most prominently used social network in the American professional realm (Forbes, 2012; 
Statista, 2016). Furthermore, the skills in LinkedIn have endorsements from other individuals - a further validation over most other data sources which rely exclusively on self-assessment.

This study focuses on identifying skills that are correlated with 'BIM.' The bivariate correlation analysis computes the correlation coefficients between skills from their number of endorsements. The authors consider skills that have at least low correlation coefficients $(\geq 0.30)$ with BIM as those that are "correlated" with BIM. This threshold is adopted because variables with correlation coefficients that are smaller than 0.30 have little correlation if any (Asuero et al. 2006).

\section{Skills commonly listed with BIM in job ads}

This analysis focuses on identifying skills that are commonly listed in the collected job advertisements. The authors consider "skills that are commonly listed" as those that are listed in at least $10 \%$ of total advertisements. This threshold was used by another paper that identified the common competencies of librarians from job advertisements (Harnett, 2014).

Additionally, this analysis groups the skills that are commonly listed into (i) skills that are necessary to acquire a particular position as 'required skills;' and (ii) skills that are not absolutely necessary, but would be an advantage in the acquisition of a specific position as 'preferred skills.' The required and preferred skills are identified using relational analysis. This study adapts the content analysis concepts on relational analysis and conceptual analysis from Carley (1990). Performing the conceptual analysis in this study can illustrate the importance of a skill from a word's number of occurrences. Conversely, the relational analysis may further explore the relationships between words, and the level of requirement of a skill by analysing each original sentence. Therefore, the authors adopt relational analysis to code the skills that are listed in the advertisements into required skills and preferred skills. The skills are coded in this analysis without interpreting their meanings. This research design is adopted from the previous effort of identifying the skills that are required and preferred in digital librarian positions (Choi and Rasmussen, 2009).
In other words, this analysis first groups the skills that are listed in the advertisements into two groups: (i) skills that are listed in at least 10\%; and (ii) skills that are not listed in at least $10 \%$ of the total number of advertisements. Then, the skills in the first group are further grouped into: (a) skills that are required more than preferred; and (b) skills that are preferred more than required. Equation 1 and Equation 2 present the formula used to compute the percentage of being listed and being required, respectively.

Percentage of being listed $=$

$\frac{\text { No of job ads with skill listed }}{\text { Total number of job ads }} \times 100 \%$

Percentage of being required $=$

$\frac{\text { No of job ads with skill listed as required }}{\text { No of job ads with skill listed }} \times 100 \%$

\section{Skills correlated with BIM in social networking profiles vs. skills commonly listed with BIM in job ads}

This study first compares the skills that are obtained through data collection. In this initial analysis, all skills obtained are compared, without grouping any that might have similar meanings. To further compare the information from the profiles and advertisements, this study groups the skills into categories. Both comparisons omit the individual skills and skill categories that are endorsed to less than $2.5 \%$ of the profiles. These omissions remove those that represent a smaller portion of the profiles. Figure 3 shows the steps taken to perform these analyses.

Skills. This initial analysis compares skills from the profiles and advertisements without any interpretation of their meaning. This approach does not introduce any subjectivity into the process, but also means that similar skills may be analysed individually. This limitation could potentially reduce the chance that a related group of skills would emerge as essential skills for industry positions because of the sub-divided nature of this raw data. 


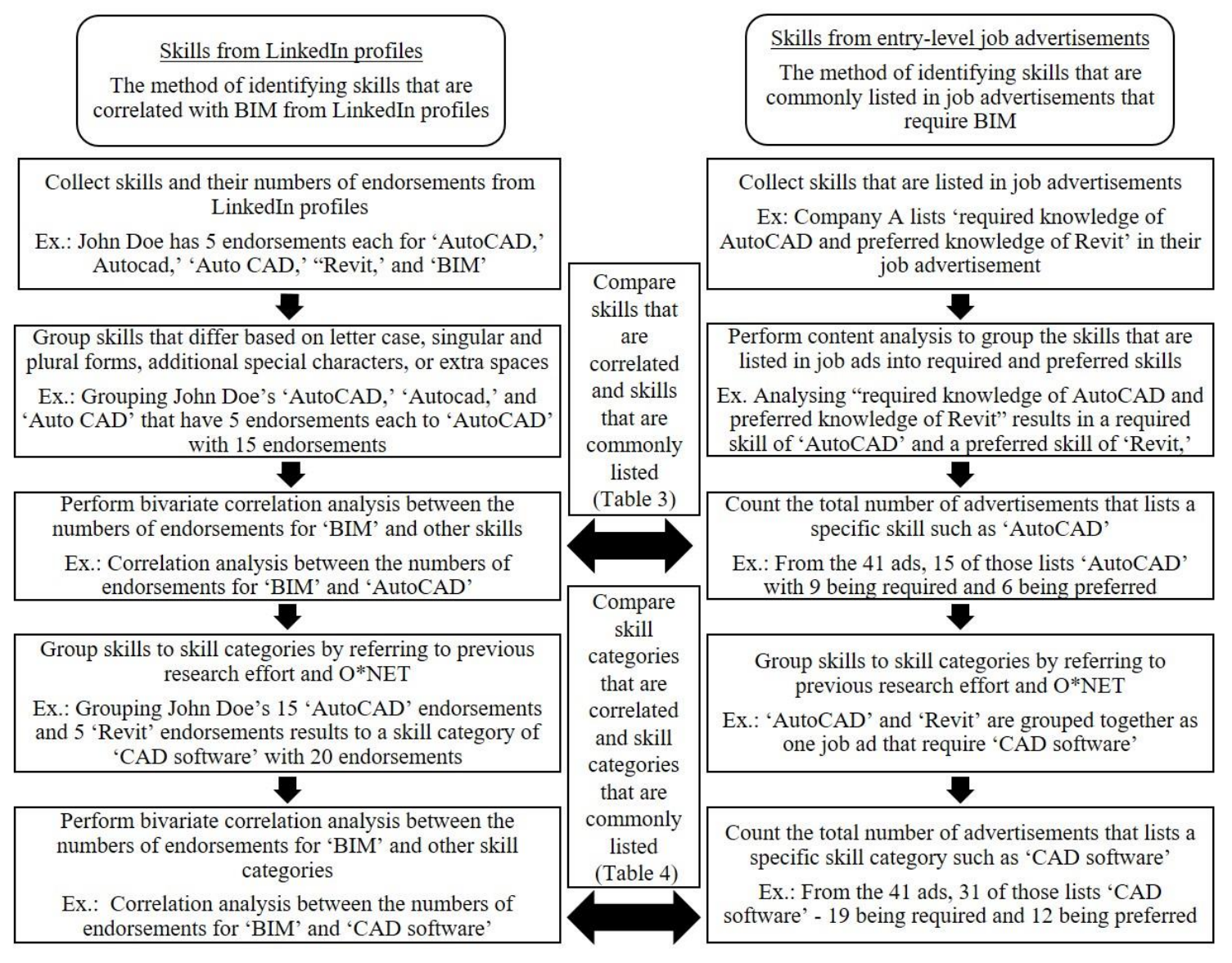

Figure 2 The process of analysing skills from social networking profiles and entry-level job advertisements 
tools

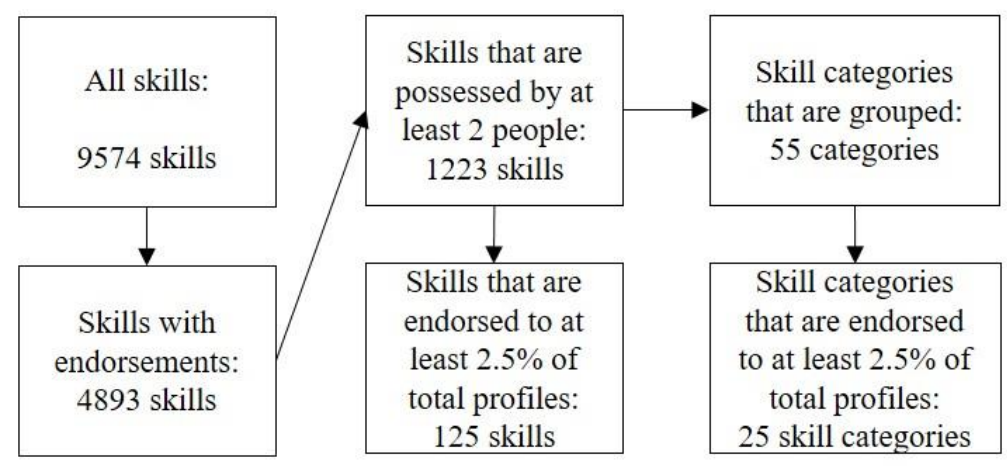

and

Figure 3 The process of grouping skills into skill categories

Skill categories. This subsequent analysis compares skills from the profiles and advertisements by grouping them into skill categories. The process of grouping skills is based on previous research efforts, and the Occupational Information Network or O*NET's database on tools and technologies, and knowledge domains. This study groups those skills by using O*NET's data because the government funded database provides information on occupation-specific descriptors including the task of tools and technologies, and the relevant skills, knowledge, and abilities. This research design of using O*NET to group skills is similar to another previous effort that categorised competencies when analysing online job postings (Uhm et al., 2017). The authors consider skills that are endorsed to only one individual as very uncommon. Therefore, the process of grouping skills involves only those that are endorsed to more than one individual.

The analysis groups the collected skills in the profiles and advertisements into skill categories. First, the soft skills are grouped by referring to the list of soft skills from previous research efforts (Giesecke and McNeil, 1999; Rainsbury et al., 2002; Leicht et al., 2009). Then, the hard skills are grouped by referring to the list of tools and technologies in $\mathrm{O}^{*}$ NET. However, O*NET lists certain tools and technologies in one or more categories. Therefore, skills that are listed in two or more categories are included in each categorization. The authors then group leftover skills into the available tools, technologies and knowledge domains that are listed in O*NET. The leftover skills that are unrelated to any of those technologies or domains are omitted from this process. The process of grouping the leftover skills requires interpretations that could potentially introduce some subjectivity into the process. To assess the reliability of the process, another researcher groups a randomly given portion $(15 \%)$ from the leftover skills separately. The results of both researchers are compared to calculate the inter-rater reliability of the process.

In addition to grouping the skills, the analysis computes the endorsements of skill categories from those in the profiles. This process first identifies the number of endorsements for each skill that is grouped together. Then, those endorsements are added up to compute the endorsements of their skill categories. The analysis also determines the level of requirement of skill categories from those in the advertisements. In this process, if any terms in a single advertisement are required, the skill categories are coded as required. Skill categories are coded as preferred only when all terms in the advertisement are listed as preferred. If those terms appeared as both required and preferred, the skill category is coded as required because an aspect of that skill would be necessary for an individual obtaining that job position.

\section{Skills possessed by novice practitioners vs. skills listed in job ads.}

The initial social network data collection process enables the researchers to explore skills that are commonly listed from among all industry professionals who work with BIM. However, this sample set also includes individuals with many 
Table 1 Summary of data collected for the social network analysis

\begin{tabular}{|c|c|c|c|c|c|c|}
\hline Characteristics & $\begin{array}{l}\text { No of } \\
\text { available } \\
\text { profiles }\end{array}$ & $\begin{array}{l}\text { No of collected } \\
\text { profiles }\end{array}$ & $\begin{array}{l}\text { No of } \\
\text { novice } \\
\text { profiles a }\end{array}$ & Characteristics & $\begin{array}{l}\text { All } \\
\text { profiles }\end{array}$ & $\begin{array}{l}\text { Novice } \\
\text { profiles }^{\text {a }}\end{array}$ \\
\hline Profiles & 6727 & 5061 & 168 & Skills & & \\
\hline City & & & & All skills & 9574 & 1355 \\
\hline Chicago & 844 & 661 & 25 & $\begin{array}{l}\text { Endorsed to more than } 2.5 \% \\
\text { individuals }\end{array}$ & 125 & 84 \\
\hline Houston & 664 & 599 & 27 & Skill categories & & \\
\hline Jacksonville & 114 & 76 & 2 & All skill categories & 55 & 35 \\
\hline Los Angeles & 1280 & 872 & 20 & Endorsed to more than $2.5 \%$ & 25 & 25 \\
\hline New York & 1478 & 770 & 15 & Experience & & \\
\hline Phoenix & 834 & 792 & 36 & Average (years) & 16.3 & 2.5 \\
\hline Seattle & 654 & 566 & 28 & Standard deviation (years) & 9.48 & 0.65 \\
\hline Washington D.C. & 859 & 725 & 15 & & & \\
\hline
\end{tabular}

${ }^{a}$ Novice profiles represents profiles with less than three years of experience

years of industry experience. Therefore, it is possible that, while this population may indicate what skills are needed for BIM implementation in general, they may not indicate a realistic set of expected goals for students pursuing entry-level positions. The data set is reduced to explore only individuals with three or fewer years of experience for subsequent analysis. This study adopts this threshold since previous studies have suggested that those with three or more years of experience are much more likely to be experts in their fields (Kiziltas et al., 2010; Wang and Leite, 2014b).

\section{Data analysis: Job tasks between positions in job ads}

This analysis compares the job tasks between BIMspecialized positions and non-BIM-specialized positions from the collected advertisements. In this analysis, the authors first categorize the advertisements into those that are BIM-specialized positions and non-BIM specialized positions. Advertisements with 'BIM' in the title are considered as those of BIM-specialized positions. Conversely, advertisements without 'BIM' in the title are considered as those of non-BIMspecialized positions. This categorization is adopted from previous research efforts that define 'BIM-specialized positions' as those with 'BIM' in the title analysis
(Barison and Santos, 2010; Wu and Issa, 2013; Davies et al. 2015).

The analysis then continues by coding the job tasks in the advertisements into simple sentences. This process of coding the job tasks groups similar tasks together. The authors then count the number of tasks that are grouped in each representative task. Several advertisements have multiple tasks that are grouped into the same task. Therefore, there are representative tasks that have a higher count compared to the number of advertisements. Finally, this analysis compares the job tasks between the BIM-specialized and non-BIM-specialized positions using those representative tasks and their counts.

In this analysis, the process of grouping the job tasks involves those that are in the advertisements. Theoretically, O*NET's database could have been used to group the job tasks. However, the database

Table 2 Summary of data collected for the job advertisement

\begin{tabular}{|ll|ll|}
\hline Characteristics & $\begin{array}{l}\text { Number of } \\
\text { observations }\end{array}$ & Characteristics & $\begin{array}{l}\text { Number of } \\
\text { observations }\end{array}$ \\
\hline Job advertisement & 41 & Skills & 122 \\
City & & Listed to more than 10\% & 11 \\
$\quad$ Chicago & 3 & Listed to less than 10\% & 111 \\
Houston & 2 & Required > preferred & 80 \\
Jacksonville & 4 & Skill categories & 28 \\
Los Angeles & 12 & Listed to more than 10\% & 14 \\
New York & 11 & Listed to less than 10\% & 14 \\
Phoenix & 2 & Required > preferred & 27 \\
Seattle & 2 & Positions & 41 \\
Washington D.C. & 5 & BIM specialized & 24 \\
& & Non-BIM-specialized & 17 \\
\hline
\end{tabular}


Table 3 Comparison between the skills that are possessed by individuals related to BIM and the skills that are commonly listed in entry-level job advertisements that require BIM ${ }^{\mathrm{a}}$

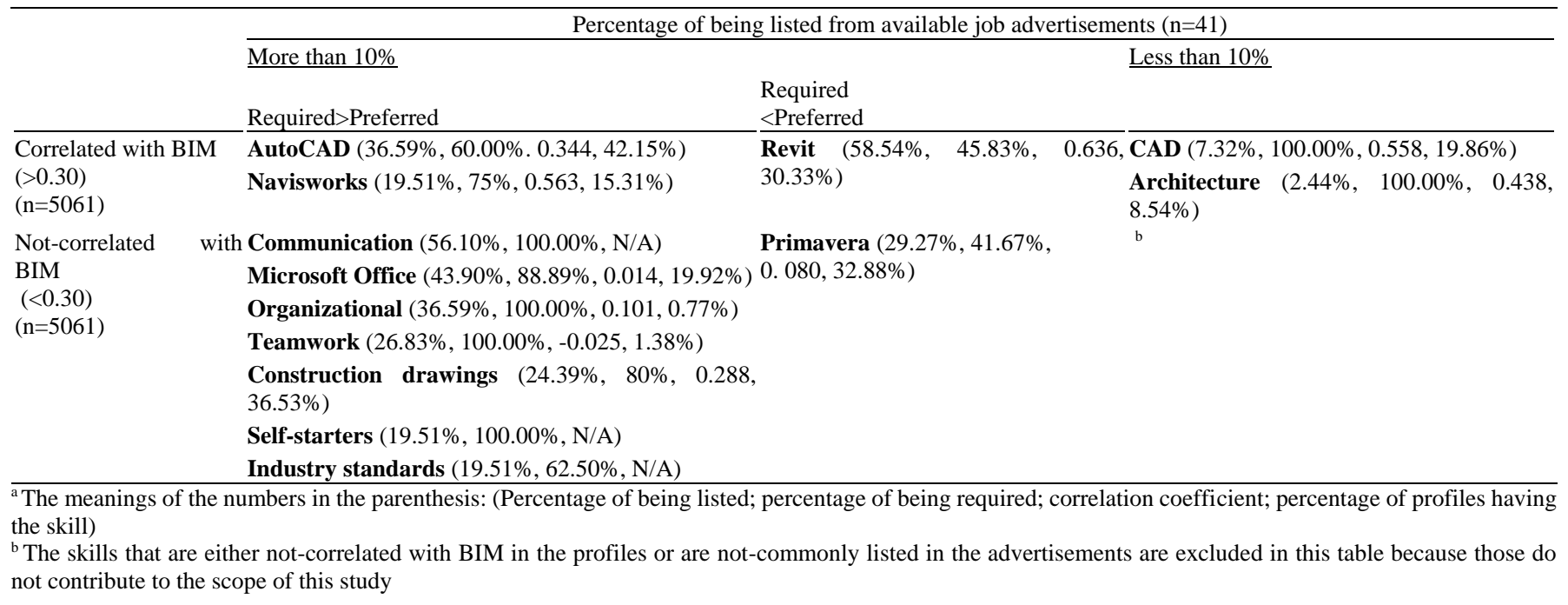

had no information on the BIM-specialized positions identified through the data collection such as BIM designers, BIM specialists, BIM technicians and BIM detailers. The authors also consider interchanging those BIM titles to CAD titles, which are the alternative titles for 'architectural drafters,' according to O*NET. However, it is risky to consider all of those BIMspecialized positions as architectural drafters, particularly when those positions are construction industry positions that do not require architectural degrees. Therefore, this analysis codes similar job tasks individually as performed by previous research efforts on analysing job advertisement content (Choi and Rasmussen, 2009; Barison and Santos, 2011).

\section{Results}

Table 1 and Table 2 shows the information of the collected data from the social networking profiles and the entry-level job advertisements, respectively. The data collection process occurred between February 27 and April 11, 2016, for the individual profiles, and between March 24 and March 31, 2016, for the job advertisements. The process of collecting data from social networking profiles includes those profiles that exist before the date of research data collection.
For the social networking profiles, the data collection gathered 5,061 profiles $(75 \%)$ from the 6,727 profiles available, ranging between $52 \%$ and $95 \%$ between the eight locations. From those profiles, 9,574 skills were identified. From those, 125 skills are endorsed to more than $2.5 \%$ of the total profiles. The process of grouping the skills resulted in 55 skill categories. From those, 25 skill categories are endorsed to more than $2.5 \%$ of the total profiles.

For the job advertisements, 41 job advertisements were gathered. From those, 24 are BIM-specialized positions, and 17 are non-BIM-specialized positions. Through the data analysis, 122 skills were identified. From those, 11 skills are listed in at least $10 \%$ of the advertisements. The process of grouping the skills resulted in 28 skill categories. From those, 14 skill categories are listed in at least $10 \%$ of the advertisements.

\section{Skills possessed by individuals vs. skills listed in job ads}

Table 3 lists and compares skills that are possessed by individuals related to BIM from social networking profiles and skills that are commonly listed in entry-level job advertisements that require BIM. The results illustrate the similarities and differences between the skills in the profiles and 
the advertisements. Overall, out of the eleven skills that are commonly listed in the advertisements, only three are correlated with BIM in the profiles. In other words, there are more differences than similarities between the skills in the profiles and the advertisements.

Additionally, the results also illustrate the existence of skills that are preferred in the advertisements. The results suggest that even though certain skills are commonly listed by employers, employers are not frequently 'requiring' these skills for entry-level hires. For example, 'Revit' and 'Primavera' are the skills that are commonly listed but are only preferred in the advertisements. These results illustrate that there are common skills that are not absolutely necessary, but would be an advantage in the acquisition of BIM-specific positions.

\section{Skill categories possessed by individuals vs. skill categories listed in job ads}

Table 4 lists and compares skill categories that are possessed by individuals related to BIM from social networking profiles and skill categories that are commonly listed in entry-level job advertisements that require BIM. The process of grouping the skills into skill categories may introduce some subjectivity. To address this problem, this research performs an inter-rater reliability test that resulted in a level of agreement of $81.3 \%$.

The results illustrate the similarities and differences between the skill categories in the profiles and those in the advertisements. Altogether, out of the fourteen skill categories that

Table 4 Comparison between the skill categories that are possessed by individuals related to BIM and the skill categories that are commonly listed in entry-level job advertisements that require BIM ${ }^{\text {a }}$

\begin{tabular}{|c|c|c|c|c|}
\hline & \multicolumn{4}{|c|}{ Percentage of being listed from available job advertisements $(\mathrm{n}=41)$} \\
\hline & \multicolumn{2}{|c|}{ More than $10 \%$} & \multirow{2}{*}{\multicolumn{2}{|c|}{ Less than $10 \%$}} \\
\hline & Required $>$ Preferred & $\begin{array}{l}\text { Required } \\
<\text { Preferred }\end{array}$ & & \\
\hline $\begin{array}{l}\text { Correlated with BIM } \\
(>0.30) \\
(\mathrm{n}=5061)\end{array}$ & CAD software $(75.61 \%, 61.29 \%, 0.639,55.88 \%)$ & NIL & & $\begin{array}{l}\text { Design } \\
(2.44 \%, 100.00 \%, 0.396 \text {, } \\
56.73 \%)\end{array}$ \\
\hline \multirow{12}{*}{$\begin{array}{l}\text { Not-correlated with B } \\
(<0.30) \\
(\mathrm{n}=5061)\end{array}$} & 1 Communication $(56.10 \%, 100.00 \%, 0.050,2.55 \%)$ & Project management software & $(31.71 \%$ & \\
\hline & $\begin{array}{l}\text { Planning and organizational }(43.90 \%, 94.44 \% \text {, } \\
0.095,1.92 \%)\end{array}$ & $46.15 \%, 0.080,49.04 \%)$ & & \\
\hline & $\begin{array}{l}\text { Office suite software }(43.90 \%, 88.89 \%, 0.015 \text {, } \\
19.92 \%)\end{array}$ & & & \\
\hline & $\begin{array}{l}\text { Building and construction }(43.90 \%, 55.56 \%, 0.150 \text {, } \\
90.14 \%)\end{array}$ & & & \\
\hline & Initiative $(41.46 \%, 94.12 \%, \mathrm{~N} / \mathrm{A})$ & & & \\
\hline & Teamwork $(31.71 \%, 100.00 \%,-0.025,1.38 \%)$ & & & \\
\hline & $\begin{array}{l}\text { Engineering and technology }(31.71 \%, 61.54 \%, 0.186 \text {, } \\
86.72 \%)\end{array}$ & & & \\
\hline & $\begin{array}{l}\text { Analytical and problem-solving }(17.07 \%, 85.71 \% \text {, - } \\
0.015,0.91 \%)\end{array}$ & & & \\
\hline & $\begin{array}{l}\text { Computer and electronics }(17.07 \%, 85.71 \%, 0.108 \text {, } \\
3.12 \%)\end{array}$ & & & \\
\hline & $\begin{array}{l}\text { Admin and management }(14.63 \%, 100.00 \%, 0.115 \text {, } \\
85.89 \%)\end{array}$ & & & \\
\hline & $\begin{array}{l}\text { Graphics or photo imaging software }(14.63 \% \text {, } \\
83.33 \%, 0.167,11.99 \%)\end{array}$ & & & \\
\hline & $\begin{array}{l}\text { Document management software }(12.02 \%, 80.00 \% \text {, } \\
0.092,2.35 \%)\end{array}$ & & & \\
\hline
\end{tabular}

a The meanings of the numbers in the parenthesis: (Percentage of being listed; percentage of being required; correlation coefficient; percentage of profiles having the skill)

b The list of other skill categories are: analytical or scientific software; communications and media; customer and personnel service; development environment software; education and training; law and government; leadership; mechanics; personnel and human resources; presentation software; production and processing; sales and marketing; spreadsheet software; transportation; and word processing software 
are commonly listed in the advertisements, only one is correlated with BIM in the profiles. In other words, there are more differences than similarities between the skill categories in the profiles and the advertisements.

In addition to illustrating the overlapping skill categories, the results also illustrate the existence of skill categories that are preferred in the advertisements. The result suggests that there is a skill set that is commonly listed, but is only preferred in the advertisements. The results also suggest that different skills in the same skill set have different levels of requirement. Specifically, 'Revit,' 'AutoCAD' and 'Navisworks' are from the same skill category of 'CAD software.' 'AutoCAD' and 'Navisworks' are commonly listed and are required in the advertisements. However, 'Revit' is commonly listed, but is only preferred in the advertisements. In other words, there are skills from the same skill set that have different levels of requirement in the advertisements.

\section{Skills possessed by novice practitioners vs. skills listed in job ads}

Table 5 and Table 6 show the comparison of skills that are possessed by novice practitioners related to BIM from social networking profiles and the skills that are commonly listed in entry-level job advertisements that require BIM. Table 5 lists the skills, while Table 6 lists the skill categories for the comparison.

The results are similar to comparing those that are possessed by all individuals related to BIM and the advertisements. Specifically, the skills and skill categories that overlap those that are commonly listed in the advertisements are the same. Overall, less than a quarter of the skill and skill categories overlap those that are commonly listed in the advertisements. Therefore, these results suggest that there are more differences than similarities between the skills in the profiles and the advertisements.

Additionally, the results illustrate that there are differences between the skills possessed by the individuals, and the novice practitioners. Specifically, the differences are between the skills

Table 5 Comparison between the skills that are possessed by novice practitioners related to BIM and the skills that are commonly listed in entry-level job advertisements that require BIM ${ }^{\mathrm{a}}$

\begin{tabular}{|c|c|c|c|}
\hline & Percentage of being & listed from available job advert & ements $(n=41)$ \\
\hline & More than $10 \%$ & & Less than $10 \%$ \\
\hline & Required $>$ Preferred & $\begin{array}{l}\text { Required } \\
<\text { Preferred }\end{array}$ & \\
\hline Correlated & AutoCAD $(36.59 \%, 60.00 \% .0 .523,48.81 \%)$ & Revit $\quad(58.54 \%, \quad 45.83 \%$, & $0.646, \overline{\text { CAD }(7.32 \%, 100.00 \%, 0.553,12.50 \%)}$ \\
\hline $\begin{array}{l}\text { with BIM } \\
(>0.30)\end{array}$ & Navisworks $(19.51 \%, 75 \%, 0.815,8.93 \%)$ & $32.14 \%)$ & $\begin{array}{l}\text { SketchUp } \\
8.33 \%)\end{array} \quad(7.32 \%, \quad 66.67 \%, \quad 0.454$ \\
\hline$(\mathrm{n}=168)$ & & & Plumbing $(0.00 \%, 0.00 \%, 0.371,5.36 \%)$ \\
\hline Not-correlatec & Communication $(56.10 \%, 100.00 \%, \mathrm{~N} / \mathrm{A})$ & Primavera $(29.27 \%, 41.67 \%$, & $\mathrm{b}$ \\
\hline with BIM & Microsoft Office $(43.90 \%, 88.89 \%,-0.055,41.67 \%)$ & 0.052 & \\
\hline$(<0.30)$ & Organizational $(36.59 \%, 100.00 \%, \mathrm{~N} / \mathrm{A})$ & $21.43 \%)$ & \\
\hline & Teamwork $(26.83 \%, 100.00 \%,-0.068,9.52 \%)$ & & \\
\hline & $\begin{array}{l}\text { Construction drawings }(24.39 \%, 80 \%, 0.237 \text {, } \\
17.26 \%)\end{array}$ & & \\
\hline & Self-starters $(19.51 \%, 100.00 \%, \mathrm{~N} / \mathrm{A})$ & & \\
\hline & Industry standards $(19.51 \%, 62.50 \%, \mathrm{~N} / \mathrm{A})$ & & \\
\hline
\end{tabular}

The Engineering Project Organization Journal (C)2017 Engineering Project Organization Society www.epossociety.org 
and skill categories that are correlated with BIM, but are not commonly listed in the advertisements. For skills, 'architecture' is correlated with BIM only in the profiles of all practitioners. 'Construction estimating' and 'SketchUp' are correlated with BIM only in the profiles of the novice practitioners. For skill categories, 'design' is correlated with BIM only in the profiles of all practitioners. In other words, the non-novice and novice practitioners have differences between their BIM skill set.

\section{Job tasks between positions in job ads}

Table 7 summarizes the results of the job tasks and their count for BIM-specialized positions and nonBIM-specialized positions. The results illustrate that certain tasks are exclusive to the BIMspecialized positions. These tasks are those that are related to the BIM-specialized positions, but are not included in the non-BIM-specialized positions. These tasks include those such as 'educate other staff on BIM' and 'advance Virtual Design and Construction (VDC) flow.' However, the authors question the sustainability of these tasks when BIM has achieved maturity throughout the industry. The maturity should result to more staff that are educated in BIM and more companies with established VDC flows. Therefore, although the results illustrate that there are exclusive tasks for BIM-specialized positions, it is not clear if these tasks are likely to remain necessary in the future.

In addition to illustrating the exclusive tasks of BIM specialized positions, the results also illustrate the main tasks of these positions. The results suggest that 'create, update and maintain models,' and 'produce specific output using BIM' are the

Table 6 Comparison between the skill categories that are possessed by novice practitioners related to BIM and the skill categories that are commonly listed in entry-level job-advertisements that require BIM ${ }^{\mathrm{a}}$

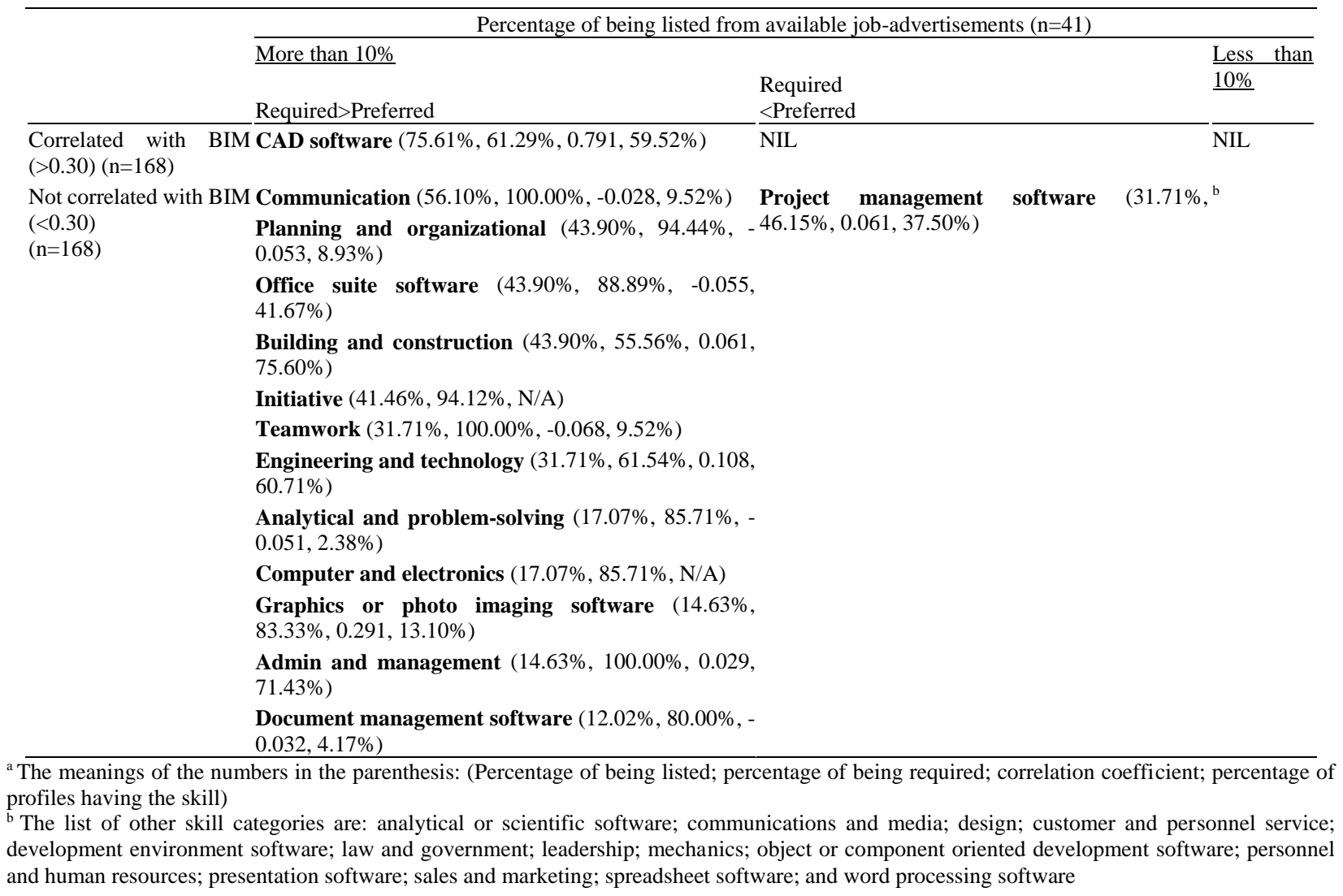

The Engineering Project Organization Journal (C)2017 Engineering Project Organization Society www.epossociety.org 
main tasks of BIM-specialized positions. These tasks have higher counts compared to all of the other tasks in BIM specialized positions. However, these tasks are similar to certain tasks related to CAD in $\mathrm{O}^{*} \mathrm{NET}$. Those similar tasks include operating $\mathrm{CAD}$ equipment to perform engineering tasks, and produce designs, working drawings, charts, forms, and records. These tasks are similar to those of non-BIM-specialized positions such as architects, project managers, and project engineers in $\mathrm{O}^{*}$ NET. In other words, the main tasks of BIMspecialized positions in the advertisements are similar to the current CAD tasks of non-BIMspecialized positions in $\mathrm{O} * \mathrm{NET}$.

\section{Discussion}

This study identifies skills that are related to BIM by analysing social networking profiles of individuals that are related to BIM and entry-level job advertisements that require BIM. Additionally, the skills from both sets of data are compared in this analysis. The results suggest that there are discrepancies between the skills that are related to BIM in this study. First, there are more differences than similarities between the skills and skill categories in the profiles and advertisements. The same findings are also illustrated when comparing the skills and skill categories that are possessed by novice practitioners from the profiles and the advertisements. Second, there are differences between the skills that are possessed by all

Table 7 Comparison of the job tasks between BIM-specialized and non-BIM-specialized positions in entry-level job advertisements that require BIM

\begin{tabular}{|c|c|c|c|c|c|}
\hline \multicolumn{3}{|l|}{ Non-BIM-specialized positions } & \multicolumn{3}{|l|}{ BIM-specialized positions } \\
\hline Task & Count & $\begin{array}{l}\text { Job ads } \\
(\mathrm{n}=17)\end{array}$ & Task & Count & $\begin{array}{l}\text { Job ads } \\
(\mathrm{n}=24)\end{array}$ \\
\hline Communicate and coordinate with others & 26 & 12 & Create, update and maintain models & 53 & 22 \\
\hline Prepare construction documents & 16 & 11 & Produce specific output with BIM c & 37 & 22 \\
\hline Oversight projects & 10 & 10 & Communicate and coordinate with others & 20 & 16 \\
\hline $\begin{array}{l}\text { Prepare reports and studies (ex. monthly reports, } \\
\text { structural studies) }\end{array}$ & 10 & 10 & Prepare construction documents a & 18 & 13 \\
\hline Review construction documents a & 8 & 7 & Resolve issues related to BIM & 16 & 11 \\
\hline Create, update and maintain models & 7 & 3 & Provide quality control for BIM & 12 & 11 \\
\hline Manage finance for projects & 6 & 3 & Perform related calculations & 10 & 4 \\
\hline Perform related calculations & 6 & 2 & Inspect existing condition & 6 & 3 \\
\hline Report issues to upper personnel & 5 & 5 & Represent company in meetings related to BIM & 5 & 5 \\
\hline Produce specific output using BIM b & 5 & 5 & Advance VDC flow in company & 4 & 4 \\
\hline Response to inquiries of construction documents a & 5 & 4 & Educate others staffs on BIM & 4 & 3 \\
\hline Inspect existing condition & 4 & 3 & Partake in project submissions & 3 & 3 \\
\hline Verify conformance to specifications & 4 & 4 & Identify issues in documents or model & 3 & 1 \\
\hline Prepare estimates & 4 & 4 & Manage issuance of drawings & 2 & 2 \\
\hline Gather construction documents & 3 & 3 & Manage construction documents a & 2 & 2 \\
\hline Prepare presentations & 3 & 3 & Coordinate material requirements & 1 & 1 \\
\hline Partake in LEED submissions & 2 & 2 & Review material requirements & 1 & 1 \\
\hline Provide consulting services & 2 & 2 & Visualize building systems & 1 & 1 \\
\hline Update project website & 2 & 2 & Distribute construction documents a & 1 & 1 \\
\hline Represent company & 2 & 2 & & & \\
\hline Update project schedule & 2 & 2 & & & \\
\hline Procure and coordinate materials & 2 & 2 & & & \\
\hline Negotiate pricing/proposals & 2 & 2 & & & \\
\hline Motivate project team members & 1 & 1 & & & \\
\hline Prepare proposals for new projects & 1 & 1 & & & \\
\hline Make technical decisions & 1 & 1 & & & \\
\hline Manage construction documents a & 1 & 1 & & & \\
\hline \multicolumn{6}{|c|}{$\begin{array}{l}\text { Construction documents represent designs, drawings, and specifications including request for information (RFI), submittals, shop drawings and } \\
\text { change orders }\end{array}$} \\
\hline
\end{tabular}


individuals and novice practitioners. Lastly, there are different levels of requirement for the skills and the skill sets in the advertisements. It is also evident that certain skills from the same skill set have different levels of requirement in the advertisements. In other words, this study has identified skills that are related to BIM. These skills are commonly sought by employers, and they are commonly reported by current BIM professionals on social networking profiles. Therefore, preparing students with these skills may support their future career success. However, the skills that are reported on social networking and those that are sought by employers do not match exactly. Therefore, this creates a need to identify which skills are the most critical for educators to incorporate into their courses. This need for prioritization of skills will be addressed in future work that aims to interview current industry experts to obtain more in-depth feedback to identify the most critical skill sets necessary to resolve the most common and impactful BIM challenges in construction.

Additionally, this study analyses job tasks from the same entry-level job advertisements that were collected. The job tasks are also compared between BIM-specialized and non-BIM-specialized positions. The analysis helps to illustrate the existence of 'BIM tasks,' which are the exclusive and main tasks of the BIM-specialized positions. However, the authors question the sustainability of these BIM tasks. Specifically, there are BIM tasks that may no longer be needed when BIM has achieved maturity throughout the industry. Moreover, there are also BIM tasks in the advertisements that are similar to the current CADrelated tasks of the non-BIM-specialized positions in O*NET. These similarities suggest that BIM tasks might diffuse into the current tasks of those non-BIM-specialized positions in the future. This change may be similar to the transition between hand-drafted drawings to CAD in the past. In other words, BIM tasks will be distributed throughout an organization. If this proves to be the case, BIM skills may no longer be a differentiator among individuals, but may simply be an expected skill set for anyone. Therefore, this study suggests that while BIM skills may be a standard expectation in all positions in the future, there are BIM tasks that may disappear when BIM reaches maturity in the industry.

While this research provides several insights into the skills that may be required for new BIM professionals, the work does have a few limitations. For example, it is possible that the job advertisements identified may be seasonal or have other variations that could influence findings. Additionally, the study design performs content analyses, which could potentially produce bias in the data through subjective categorization. While this is theoretically possible, this work required minimal analysis and had a high level of agreement between the researchers performing the categorization. Also, interpreting the skills occurs only during the process of grouping skills that are unlisted from previous research effort on soft skills, and $\mathrm{O}^{*}$ NET's database. The process groups leftover skills in general domains with specific definitions provided by the database. Some may argue that grouping certain skills may inflate those skills in having a higher percentage of being listed in the job advertisement analysis. However, from the results, even certain skills with more terms are listed at less than $10 \%$. Additionally, the percentage of being listed is solely based on the number of job advertisements, therefore grouping multiple terms for a skill does not increase the percentage. This study can be repeated as a longitudinal study to explore the trends related to BIM skills possessed by individuals and job tasks listed in job advertisements. Also, future studies may further investigate the BIM-specialized and non-BIM-specialized positions by comparing the skills that are possessed by industry professionals or the skills that are listed in job advertisements.

\section{Conclusion}

This study identified the skills that are related to BIM by analysing social networking profiles and entry-level job advertisements. Additionally, job tasks in those advertisements were analysed to illustrate how the skills might be used in the industry. The analysis also compared the job tasks between the BIM-specialized and non-BIMspecialized positions to illustrate the different tasks between those positions further. This paper 
contributes to the current body of knowledge in two ways. The first contribution is indirectly providing findings related to the skills required for individuals pursuing entry-level BIM positions in construction. The second contribution is in the research design of this study, which uses publiclyavailable data sources to assess current skills of individuals in serving the present needs of employers.

On the surface, it would seem logical that the skills sought by employers would closely match those that are currently possessed by individuals in the industry. However, it is noteworthy to observe that the results of this study suggest that there are differences between the skills that were identified. The results also suggest that while BIM skills may be a standard expectation in all positions in the future, there are BIM tasks that may disappear Therefore, prioritizing the skills may prepare students with those that are more sustainable throughout their career.

Based on these findings, future work will aim to identify the best methods of prioritizing the skills identified in this work. Additionally, the transition of BIM tasks in non-BIM-specialized positions might require BIM education throughout the construction engineering and management curricula instead of a stand-alone course. Future work will also aim to determine the best methods for preparing students with the skills identified in this work to meet the expectations of the industry. Further advancement of BIM education may prepare students with the appropriate BIM skills, and the ability to perform BIM tasks that may improve project success and career success.

\section{References}

Asuero, AG, Sayago, A, and Gonzalez, AG (2006). "The correlation coefficient: An overview." Critical reviews in analytical chemistry, 36(1), 41-59.

Azhar, S (2011). "Building information modeling (BIM): Trends, benefits, risks, and challenges for the AEC industry." Leadership and Management in Engineering, 11(3), 241-252.

Barison, MB, and Santos, ET (2010). "An overview of BIM specialists." Computing in Civil and Building Engineering, Proceedings of the ICCCBE2010, 141.
Barison, MB and Santos, ET (2011). "The competencies of BIM specialists: a comparative analysis of the literature review and job ad descriptions." In Proceedings of International Workshop on Computing in Civil Engineering, ASCE, Reston, VA, pp. 594-602.

Bryde, D, Broquetas, M and Volm, JM (2013). "The project benefits of building information modelling (BIM)." International Journal of Project Management, 31(7), 971-980.

Carley, K (1990). "Content Analysis." The Encyclopaedia of Language and Linguistics, Pergamon Press, Edinburgh.

Chiang, JKH and Suen, HY (2015). "Self-presentation and hiring recommendations in online communities: Lessons from LinkedIn." Computers in Human Behavior, 48, 516-524.

Choi, Y and Rasmussen, E (2009). "What qualifications and skills are important for digital librarian positions in academic libraries? A job advertisement analysis." The journal of academic librarianship, 35(5), 457-467.

Davies, K, McMeel, D, and Wilkinson, S (2015). "Soft skill requirements in a BIM project team."

Forbes (2012). "Your LinkedIn Intervention: 5 Changes You Must Make."

Fox, S and Hietanen, J (2007). "Interorganizational use of building information models: potential for automational, informational and transformational effects." Construction Management and Economics, 25(3), 289-296.

Giesecke, J and McNeil, B (1999). "Core competencies and the learning organization."

$\mathrm{Gu}, \mathrm{N}$ and London, $\mathrm{K}$ (2010). "Understanding and facilitating BIM adoption in the AEC industry." Automation in construction, 19(8), 988999.

Hartnett, E (2014). "NASIG's Core Competencies for Electronic Resources Librarians revisited: An analysis of job-advertisement trends, 2000-2012." The Journal of Academic Librarianship, 40(3), 247258.

Kiziltas, S, Akinci, B, and Gonzalez, C (2010). "Comparison of experienced and novice cost estimator behaviors in information pull and push methods." Canadian Journal of Civil Engineering, 37(2), 290-301.

$\mathrm{Ku}, \mathrm{K}$ and Taiebat, $\mathrm{M}$ (2011). "BIM experiences and expectations: the constructors' perspective." International Journal of Construction Education and Research, 7(3), 175-197.

Leicht, RM, Lewis, A, Riley, DR, Messner, JI and Darnell, B (2009). "Assessing traits for success in individual and team performance in an engineering 
course." In Proceedings of Construction Research Congress 2009, ASCE, Reston, VA, pp.1358-1367.

Merschbrock, C and Munkvold, BE (2015). "Effective digital collaboration in the construction industry-A case study of BIM deployment in a hospital construction project." Computers in Industry, 73, 17.

Peterson, F, Hartmann, T, Fruchter, R and Fischer, M (2011). "Teaching construction project management with BIM support: Experience and lessons learned." Automation in Construction, 20(2), pp.115-125.

Pérez-Rosés, H and Sebé, F (2015). "Synthetic generation of social network data with endorsements." Journal of Simulation, 9(4), 279286.

Pérez-Rosés, H, Sebé, F and Ribó, JM (2016). "Endorsement deduction and ranking in social networks." Computer Communications, 73, pp.200210.

Rahman, RA, Alsafouri, S, Tang, P and Ayer, SK (2016a). "Building Information Modeling Skills For Career Success." In Proceedings of the 10th BIM Academic Symposium \& Job Task Analysis Review, Orlando, FL, pp.35-42.

Rahman, RA, Alsafouri, S, Tang, P and Ayer, SK (2016b). "Comparing Building Information Modeling Skills of Project Managers and BIM Managers Based on Social Media Analysis." Procedia Engineering, 145, 812-819.

Rainsbury, E, Hodges, D, Burchell, N and Lay, MC (2002). "Ranking workplace competencies: Student and graduate perceptions." Asia-Pacific Journal of Cooperative Education, 3(2), 8-18.

Sacks, R and Pikas, E (2013). "Building information modeling education for construction engineering and management. I: Industry requirements, state of the art, and gap analysis." Journal of Construction Engineering and Management, 139(11), 04013016.

Statista (2016). "U.S. market share of leading social media websites 2016." Available at: http://www.statista.com/statistics/265773/marketshare-of-the-most-popular-social-media-websitesin-the-us/ (accessed 30 July 2016)

Succar, B (2009). "Building information modelling framework: A research and delivery foundation for industry stakeholders." Automation in construction, 18(3), 357-375.

Succar, B, Sher, W and Williams, A (2013). "An integrated approach to BIM competency assessment, acquisition and application." Automation in Construction, 35, 174-189.

Uddin, MM and Khanzode, AR (2013). "Examples of How Building Information Modeling can enhance career paths in construction." Practice Periodical on Structural Design and Construction, 19(1), 95-102.

Uhm, M, Lee, G, \& Jeon, B (2017). "An analysis of BIM jobs and competencies based on the use of terms in the industry." Automation in Construction, 81, 6798.

Wang, L and Leite, F (2014a). "Process-oriented approach of teaching building information modeling in construction management." Journal of Professional Issues in Engineering Education and Practice, 140(4), 04014004.

Wang, L, and Leite, F (2014b). "Comparison of Experienced and Novice BIM Coordinators in Performing Mechanical, Electrical, and Plumbing (MEP) Coordination Tasks." Construction Research Congress 2014, 21-30.

$\mathrm{Wu}, \mathrm{W}$, and Issa, R R (2013). "BIM education and recruiting: Survey-based comparative analysis of issues, perceptions, and collaboration opportunities." Journal of professional issues in engineering education and practice, 140(2), 04013014.

Zide, J, Elman, B and Shahani-Denning, C (2014). "LinkedIn and recruitment: How profiles differ across occupations." Employee Relations, 36(5), 583-604. 